\title{
Review and Prospect of Quantum Management
}

\author{
Xinyi Yin \\ School of Management, Jinan University, Guangzhou, China \\ Email: yinxinyi@stu2017.jnu.edu.cn
}

How to cite this paper: Yin, X.Y. (2019) Review and Prospect of Quantum Management. American Journal of Industrial and Business Management, 9, 2220-2230. https://doi.org/10.4236/ajibm.2019.912147

Received: November 28, 2019

Accepted: December 16, 2019

Published: December 19, 2019

Copyright $\odot 2019$ by author(s) and Scientific Research Publishing Inc. This work is licensed under the Creative Commons Attribution International License (CC BY 4.0).

http://creativecommons.org/licenses/by/4.0/

\begin{abstract}
Quantum management is the combination of quantum theory and management science, as well as the application of quantum thinking in management science. Some studies have emphasized the importance of quantum management to individuals, organizations, and society. Comparing with Newtonian management, quantum management has received academic attention in recent years. This paper reviews the theoretical system of quantum management research, discusses its impact on the organization, pointing out the future research direction and practical role of quantum management.
\end{abstract}

\section{Keywords}

Quantum Management, Quantum Thinking, Newtonian Management

\section{Introduction}

Ruimin Zhang once again emphasized "Integrating Order with Personnel" model at the annual meeting of Haier group in January 2017. In Haier, the traditional top-down management model has long been broken and replaced by small and micro platform organizations. In the era of rapid change, uncertainty, self-organization, collaboration and innovation have become key words of enterprise management. More and more companies are realizing the importance of changing Newtonian thinking which lays emphasis on laws, rules, and control. This change and innovation led to a new kind of management, namely quantum management.

Quantum management was first proposed by Danah Zohar [1]. What exactly is quantum management? How is it born and applied? What are its characteristics? What are the difference and connection between it and traditional management? What is the impact on management? In order to answer the above questions, this paper is intended to review related researches on quantum management. To ensure the collection of all references to quantum management as 
far as possible, the following two points are taken as the selection criteria in this paper.

1) The research content involves quantum management and quantum thinking.

2) Application literature for the practice of quantum theory in enterprise management. Therefore, this paper has collected more than 30 literatures. Based on related references, quantum management's generation, characteristics, difference from traditional management, practice in management and future research direction are described. This paper aims to help scholars and entrepreneurs better understand the research progress, application and future research direction of quantum management.

\section{Definition of Quantum Management}

Quantum Management, derived from Quantum theory, is a combination of Quantum theory and Management science. It is also the application of Quantum thinking in Management science. With the development of quantum theory in the fields of physics, biology, chemistry, etc., quantum theory has expanded to human consciousness and psychology, and eventually attracted the attention of management scholars and entrepreneurs, entered the field of management science, and formed a unique knowledge system of quantum management.

As an important concept of modern physics, quantum was first proposed by the German physicist Planck to explain experimental phenomena in blackbody radiation in 1900. Einstein further developed the concept of quantum and put forward the light quantum hypothesis in 1905. Bohr successfully applied the quantum concept to the hydrogen atom system and founded Bohr's atomic model based on Rutherford's atomic model in 1913. Broglie proposed matter wave and pointed out that matter has a wave-particle duality in 1924. Quantum mechanics that describes the world of microscopic physics was born on 1925-26. Since then, quantum has been used to explain the basic laws of the microscopic material world and applied in medicine, chemistry, biology and other fields as well [2] [3].

Starting from the concept of quantum theory, quantum theory is considered to relate to Complementarity of the biology and psychology. Some scholars have conducted experimental studies on the connection between human thought and quantum theory [4] [5] [6]. Quantum theory is then extended to apply to human cognition and decision-making, using axiomatic system of Kolmogorov's probability theory or using geometric framework for general statistics to explain differences in human cognition and decision-making. In this kind of research on decision-making and cognitive application of quantum theory, researchers have found that the use of quantum methods, such as quantum interference, quantum projection and quantum entanglement, can better explain the differences between people's judgments and decisions than traditional behavioral models [7]. Since then, quantum cognitive model has been gradually applied to the fields of 
human consciousness and psychology that are difficult to be explained by simple information processing.

Quantum theory can affect people's decision making and cognition. Does it affect the fate of enterprises? The development and application of quantum theory led to a major change in management philosophy, which made possible the "knowledge worker" in IT industry put forward by Drucker. It causes a series of changes in management thinking [8]. For example, some studies have considered the similarity between "quantum funds" and financial markets, and applied quantum theory to business management, breaking through the traditional management model [9]. The leaders of Kelihua Company take quantum thinking as a theory to guide practice and integrate it into enterprise culture for enterprise management and software innovation. In the process of enterprise innovation and life innovation, there is often a turning point, which is actually a new change after people break through the binary thinking view and the linear thinking mode based on Newtonian mechanics [2] [10]. Before the arrival of new breakthrough, Oriental people have traditional, limited and fixed thinking, while the future development needs diversified quantum thinking [11]. Quantum theory and quantum thinking have actually become a more universal theory and mode of thinking with the nature of world view to affect people's thinking and action [12] [13]. The German scientist Heisenberg once said that the most fruitful development in the history of human thought has almost always occurred at the meeting of two different ways of thinking. It is the intersection of quantum thinking and traditional management thinking that leads to the innovation of management mode and the generation of quantum management. It is a bold attempt to combine the latest development of quantum theory with the ancient oriental civilization and think about management from a new perspective [14]. By learning new life and organizational skills in the new era, we can achieve quantum leaps. It does not require external forces or manipulations, but come from changes in internal consciousness [2]. As mentioned by Dana Zuhar, founder of quantum management, in his books "quantum self", "quantum society" and "quantum leadership", quantum theory has stepped into the field of self-organization and will have a profound impact on the field of management science. Just as Newtonian science gives rise to an all-embracing Newtonian world view, quantum science will also lay the foundation for a new world view in the quantum age [15].

\section{Characteristics of Quantum Management}

In quantum theory, the world is regarded as an inseparable whole. There is a subtle connection between the particles that make up the objective matter. The movement of each particle is irregular and unmeasured. The movement of each particle is irregular and unpredictable. After random particles collide, they will produce predictable combinations and changes, and then form new things [16]. However, in management science, management activities involve all kinds of 
unmeasurable elements, which are closely related to each other just like particles. In addition, there are also random unmeasurable combinations and changes among various elements, thus generating new elements. That is similar to quantum theory and is also the basic point of quantum management.

As mentioned in quantum mechanics, there is an energy that keeps things moving continuously, which makes things constantly change from waves to particles, and from particles to waves, and finally forms atoms, fractions and our material world.

Quantum movement changed the objectivity of Newton type, predictability, turned into a quantum subjectivity and unpredictability.

Dana Zuhar gave a comprehensive description of the characteristics of quantum management, which can be summarized into 7 points [17]:

1) Integrity: Enterprise organizations are interrelated and mutually defined in the global environment.

2) Flexibility: Quantum management system is complex and uncertain. It is between order and chaos, between wave and particle state, between existence and potential. Therefore, quantum management must be very flexible and the edge becomes very fuzzy.

3) Bottom-up, self-organizing and emerging: Quantum system is creative and new things are emerging all the time. Therefore, quantum management must carry out organizational innovation through individual creative resources.

4) Plurality: Quantum management has multiple choices to adapt to the multiplicity and diversity of society, market and individuals.

5) Improvisation: Quantum management is like conducting a symphony orchestra. Given the basic framework, individuals can play freely in uncertainty.

6) Fun and value-seeking: Quantum management recognizes the value of meditation, daydreaming, and daydreaming. It supports play and reward, and supports the pursuit of dreams and life meaning.

7) Participative: Quantum management has changed the symbiosis between humans and the environment, and transformed it into create own life and environment.

With the rapid development of the Internet technology, the limitation of time and space has been broken and everything is more closely connected. This phenomenon is like the interconnected particles in quantum theory, which are full of uncertainty and unpredictability. The significant value of quantum management and the characteristics of quantum management make it adapt to the information era, hence it can play a huge role in the current society and economy [2] [18].

\section{The Difference and Connection between Quantum Management and Traditional Management}

In the 1960s, science moved from simplicity to complexity. Newton's scientific theory explains the system in a very simple way, believing that the system is li- 
near, predictable, controllable and isolated. It is composed of independent operational parts, which can be disassembled for analysis [2]. And so far, most enterprises still do not realize that they are still using simple Newtonian management model, and this model has been unable to adapt to the development of today's society. What's the difference between quantum management and traditional management? Next, we will integrate the studies of various scholars to compare and elaborate quantum management with traditional management.

The thinking structure and process of human brain are considered to have two kinds of thinking structure: serial thinking and associative thinking. Serial thinking is a kind of continuous, one-to-one, logical, rational, goal-oriented and problem-solving thinking. It is also called "left-brain thinking" [2] [18]. Associative thinking is based on the emotional and physical center of thinking. It helps us identify patterns, learn skills, form habits and emotional connection, storage tacit knowledge which cannot communicate through rules and instructions. This thinking corresponds to the right side of the human brain, which is also known as "left and right brain division of labor theory" [19]. These two kinds of thinking have been applied to computer systems and have been clarified by sociologists and organization theorists. However, there are few connections between quantum theory and brain structure. Now let's approach a new mode of thinking, namely quantum management thinking. Quantum management thinking refers to the integration of serial and associative thinking through the neural shock of quantum changes. It is responsible for our creative, insightful, introspective thinking, proposing new concepts and models, challenging old stereotypes and mental models. Besides, it helping us adapt to rapid change and new environments [20].

In the mechanical age of the last century, everything was mostly standardized and orderly. Management at that time also adopted Newtonian management and Newtonian management thinking corresponds to our left-brain thinking. Under the management of Newtonian mode, the organization is regarded as a mechanical and Newtonian particle state.

Newton once discussed the state of Newtonian particles. He compared billiard balls to the smallest unit atoms of matter, which are independent in space and time. Particles move elastically in the air, because the forces and reactions are interrelated. After that, the west often used billiards to compare the self and billiards game is used to compare the organization. Therefore, these atoms are in an unbreakable boundary and don't fit into each other. When they collide, at least one of them will deviate from its original trajectory. However, in quantum management, the world is made up of energy balls. When the energy balls collide, they will not bounce away, but integrate and influence each other, bringing different energy changes. Therefore, unpredictable combination changes will be generated and various new things will be derived, which contain powerful potential power. Newtonian management emphasizes laws, rules, control, static and unchanging. Dana Zuhar says there is nothing wrong with Newtonian 
thinking, but there are limits that Newton's thinking has been difficult to adapt to the information age. However, quantum management attaches importance to uncertainty, potential and opportunity, and emphasizes dynamics and changes [2]. Such quantum management is a new mode that combines left and right brain thinking and connects east and west management. In the 21 st century, the global connection is getting closer and closer. Western management emphasizes the individual, while eastern management emphasizes the group. Now what we need most is the combination of the east and the west. It just like the quantum management thinking generated by the combination of the left and right brains, which will be the endless energy and power for enterprises.

\section{Practice of Quantum Management}

In 1997, Chaodi Song who is the founder of Beijing Kelihua education software group put into action the application of quantum thinking in management and put forward a set of "quantum theory" of IT industry. Chaodi Song took quantum theory as the guidance when carrying out various enterprise behaviors. $\mathrm{He}$ believed that applying quantum theory to information industry and future knowledge economy and society must be a breakthrough of traditional mode and a historical leap. In Kelihua's enterprise, there is no traditional management. Chaodi Song believes that people's "management" is restricted and creativity is also restricted. Therefore, he emphasizes that enterprise management should be enjoyable and fun. Although the quantum management knowledge system at that time was not perfect, Chaodi Song adopted quantum theory in enterprise management. The ideas and viewpoints he mentioned are already very forward-looking and in line with the characteristics of quantum management, such as fun, improvisation and diversity [21] [22] [23].

When Volvo's manufacturing hit a bottleneck, the leaders sought to break through. They found that the cars produced by Volvo production line were always similar in appearance but very different in interior. Only a few parts were common, leading to high production costs. The company realized that the ideal case would be the opposite. A car looks different but shares the same internal parts. Therefore, they set up a special team so that engineers from different departments could work together. Volvo first considered a hierarchical, well-structured mechanical work model (showing in Figure 1), in which different engineers are divided into different groups. Each group has clear task boundaries and is subject to superior supervision. After that, Volvo borrowed the internal successful quantum management model and proposed a new quantum learning model (showing in Figure 2) [2] [18]. Based on the new learning model, Volvo conceived the famous "quantum circle" team. The engineers were divided into 12 groups and each group is responsible for the design of parts is different. There are also smaller groups within these 12 groups, which, like particles in a quantum, can move independently regardless of the size of the group (showing in Figure 3). There is no special supervision, leadership and no clear boundary in 


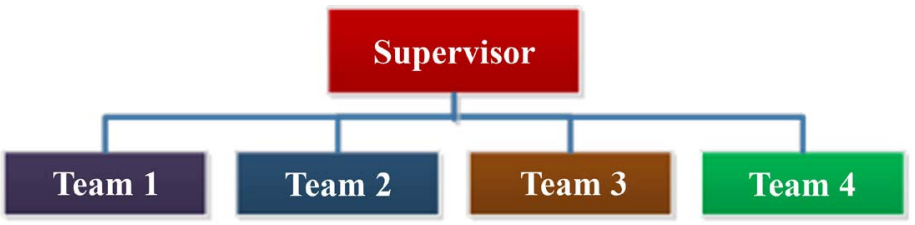

Figure 1. Volvo's hierarchical management model.

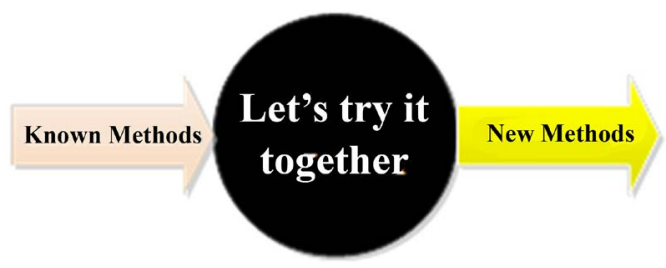

Figure 2. Volvo's quantum learning model.

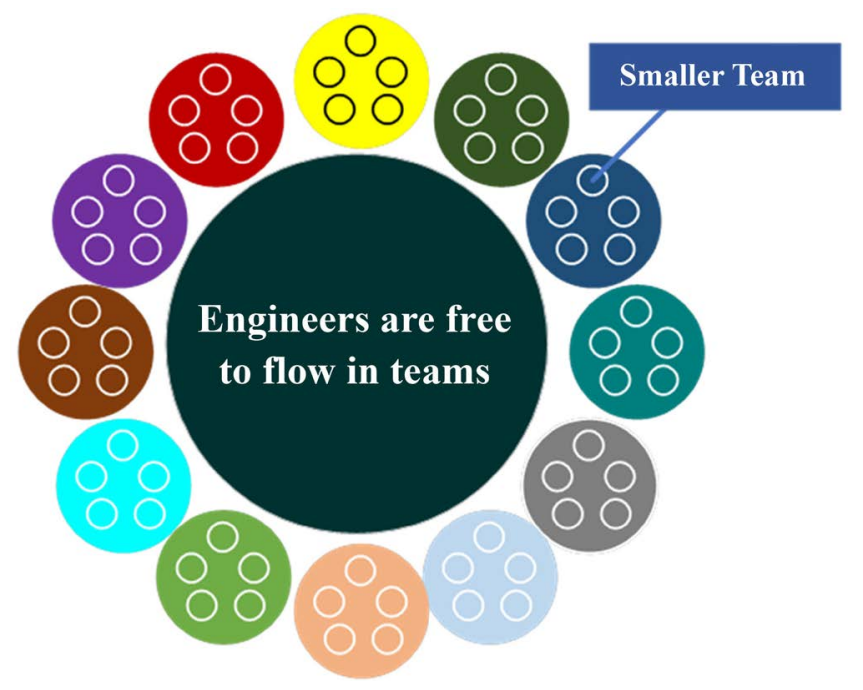

Figure 3. Volvo's “quantum circle” model.

this team. They just have the basic framework and the common overall vision, which reflects the integrity, improvisation, value pursuit and other characteristics of quantum management [24] [25].

Inspired by Heisenberg's uncertainty principle, Ruimin Zhang, CEO of Haier group, once again changed the organizational structure of Haier group, forming a platform-type organization with small and micro as the basic operating unit. Ruimin Zhang calls these "energy balls", which show different potentials according to their different environments. In December 2014, "air rubik's cube" was born on Haier's Internet transformation platform of "full maketization". The new product created by "xiaowei", after interactive communication with 810,000 users, took only six months from product design, development to product formation, and then realized mass production by the eighth month. Zhang Ruimin was inspired by Heisenberg's uncertainty principle. Such innovation scale and the speed of research and development are hard to imagine in the traditional manufacturing industry [26] [27]. The development of small and micro 
devices on Haier platform is just like the tentacles of quantum extending into the future. Every little antenna is exploring and tapping potential in the infinite user demand [28]. Haier allows failures. If small and micro failures occur, team members will return to the talent pool and rebuild small organizations based on new ideas. Changes come very fast in Haier. Haier is not only promoting internal development, but also pulling external participation. From Maker to small and micro, Haier has continuously promoted the practice of quantum management and the quantum thinking of employees' "participation is the world". Now, Haier is turning into a quantum company, not only in Zhang Ruimin's management, but also in every employee of Haier.

\section{Directions for Future Research}

Although quantum theory has been applied in various fields since the 19th century, the combination of quantum theory and management is rare. Quantum management can be said to be a new management theory, gradually gaining the attention of scholars. The construction and practice of quantum management theory have made some progress, but the empirical research is very limited. In this paper, the connotation, characteristics and practice of the concept of quantum management are sorted out and summarized. It is found that most of the previous researches on quantum management are conceptual, and there are few relevant researches. According to the current theoretical and empirical research progress, quantum management has a large research space. The following aspects will be paid attention to in the future research on quantum management:

1) Further expanding the connotation and dimension of quantum management

At present, scholars mainly focus on the characteristics of quantum management and its relationship with quantum mechanics or traditional management mode, but there are few studies on this aspect. Since the concept of quantum management originated from quantum theory and overturned the previous Newtonian thinking, researchers tend to study the connection and difference between quantum management and quantum theory and the difference of their think mode [29]. However, there is still no exact definition and dimension division of quantum management. It can see that the research on quantum management is still in the preliminary stage. The research on the deep definition, dimension, scope and influencing factors of quantum management needs to be improved, which is also the direction that we should focus on in the future.

\section{2) Exploring the theoretical framework of quantum management}

Different from the strong development of quantum thinking in physics, quantum thinking in management research only gradually known in recent years. Unlike Newton type of management theory of enterprise performance, management, and variables, the research of quantum management didn't get equal value in empirical research [30]. The concept system of quantum management is not perfect yet, and researchers' research also leans towards the concept of quantum 
management. There is still a lack of relevant research on the construction of theoretical framework and empirical research.

3) The relationship and difference between quantum management and different organizations

There are many companies that adopt quantum management theory for business practice. In addition to the mentioned Kelihua, Volvo and Haier, many enterprises also apply quantum thinking in business management. However, most leaders today don't have a clear concept of quantum management and don't focus on it. There are also leaders who pay attention to the practice of quantum management. Ruimin Zhang developed a small and micro platform through quantum management. According to literature review, quantum theory has been preliminarily tried in education software, automobile manufacturing, Haier's Maker incubator platform, supermarkets and other industries. How applicable is quantum management in different enterprises, and what are the differences and connections between them? Therefore, attention should be paid to the relationship and difference between quantum management and different organizations in the future.

4) Exploring the practice of quantum management in the context of big data

The current era is the era of big data, taking big data as a basic strategic resource. It speeds up the sharing and opening of data resources, development and application, and helps industrial transformation, upgrading and innovation. In addition, management combined with quantum thinking can play a more effective role in the context of big data. How to further mine information with big data to create and innovate can also be a direction of future research.

As an emerging management concept, quantum management can certainly bring positive results to individuals, organizations and social economy. The further research should pay more attention to quantum management and apply it to the organization and management activities to give full play to its practical value scientifically and effectively.

\section{Conclusion}

This paper analyzes the origin and connotation of quantum management, and points out future research directions. This paper reviews and prospects the related research of quantum management from the origin, characteristics, connections and differences of traditional management, the practical application of quantum management, and future research directions.

\section{Acknowledgements}

Thanks to the teachers and classmates of the school and the people who helped me.

\section{Conflicts of Interest}

The author declares no conflicts of interest regarding the publication of this paper. 


\section{References}

[1] Dana, Z. (2017) Quantum Leader. Mechanical Industry Press, Beijing.

[2] Charlotte, S. (2008) Quantum Leap: 7 Quantum Techniques That Change Your Work and Life. China Finance and Economics Press, Beijing.

[3] Cheng, G. (2017) Quantum Leadership and Service Leadership. Business Management, No. 7, 41-42.

[4] Alestell, R. (2000) Quantum Physics: Fantasy or Reality. Jiangsu People's Publishing House, Nanjing.

[5] Ashtiani, M. and Azgomi, M.A. (2015) A Survey of Quantum-Like Approaches to Decision Making and Cognition. Mathematical Social Sciences, 75, 49-80. https://doi.org/10.1016/j.mathsocsci.2015.02.004

[6] Da, D. (2015) Quantum Thinking Promotes the "Internet" Era of Textile. China Textile, No. 8, 133-135.

[7] Jiang, C.X. (2015) Quantum Thinking. Enterprise Research.

[8] Sun, Y. (2006) If Einstein Was Doing Management Consulting. Software World, 22-95.

[9] Li, M. (2012) Pay Attention to Hidden Order-Viewing Management from the Perspective of Quantum Mechanics. Leadership Science, No. 8, 49-51.

[10] Karen, B. and Durham, N.C. (2007) Meeting the Universe Halfway: Quantum Physics and the Entanglement of Matter and Meaning. Duke University Press, Durham, 212-218. https://doi.org/10.1215/9780822388128

[11] Mcqueen, K.J. (2017) Is QBism the Future of Quantum Physics? American Journal of Physics, 85, 635-683.

[12] Qiu, E.N., et al. (2012) Research on the Mode of Knowledge Innovation Based on Quantum Theory. Science \& Technology Progress and Policy, 13, 144-148.

[13] Richmond, S. (2017) Everyone Can Understand Quantum Mechanics-Really? Science \& Education, 26, 1079-1083. https://doi.org/10.1007/s11191-017-9936-9

[14] Hu, Y. (2016) Chinese Wisdom in the Quantum World. Enterprise Research.

[15] Wang, X.Y. (2016) The Internet Transformation of Operators Can Learn from the Thinking of Quantum Management. People's Posts and Telecommunications.

[16] Delbecq, A.L. (2005) Spiritually-Informed Management Theory. Journal of Management Inquiry, 14, 242-246. https://doi.org/10.1177/1056492605276844

[17] Zhong, X.S. and Rao, G.B. (2005) The Emergence and Characteristics of Quantum Thinking Mode and Its Enlightenment on Contemporary Society. Journal of Nanchang Institute of Aeronautical Technology (Social Science Edition), 2, 43-45.

[18] Zohar, D. (1995) A Quantum Mechanical Model of Consciousness and the Emergence of? Minds and Machines, 5, 597-607. https://doi.org/10.1007/BF00974988

[19] Ma, W. (2016) "Quantum Thinking" in the Era of Complex Business. Chinese Entrepreneurs, 23, 110-111.

[20] Peng, J.F. (2017) Quantum Thinking: Changing the Brain for Management System. Human Resources, 10, 20-23.

[21] Dong, H. (1998) Managing Enterprises with Quantum Thinking-Interview with Song Chaodi, President of Beijing Kelihua Education Software Group. Sino-Foreign Management.

[22] Wang, Y.L. (1998) Quantum Theory—Song Chaodi's "Nuclear Energy". China Science and Technology Monthly. 
[23] Wen, A. (1998) Song Chaodi's Breakthrough and Exploration of Quantum Management. Cover Story.

[24] Wu, B.F. (2013) Quantum Thinking. Enterprise Research.

[25] Dyck, B. and Greidanus, N.S. (2016) Quantum Sustainable Organizing Theory. Journal of Management Inquiry, 26, 32-46. https://doi.org/10.1177/1056492616656407

[26] Zhuang, W.J. and Zhu, L. (2015) What Is Haier's "Xiaowei" Subverting. Chinese and Foreign Management, No. 1, 41-42.

[27] Xia, J. (2014) Meditation and Quantum Thinking. Journal of Social Science, 8, 1-2.

[28] Jiang, B.R. (2016) Micro-Management. China Business Press, Beijing.

[29] Heshami, K., et al. (2016) Quantum Memories: Emerging Applications and Recent Advances. Journal of Modern Optics, 63, 2005-2028. https://doi.org/10.1080/09500340.2016.1148212

[30] Dür, W., Lamprecht, R. and Heusler, S. (2017) Towards a Quantum Internet. European Journal of Physics, 38, Article ID: 043001. https://doi.org/10.1088/1361-6404/aa6df7 